\title{
Enhancing Idiom Competence of Iranian EFL Learners: Idiom Etymology and Short Story in Focus
}

\author{
Omid Tabatabaei \\ English Department, Isfahan (Khorasgan) Branch, Islamic Azad University Isfahan (Khorasgan), Iran \\ E-mail: tabatabaeiomid@yahoo.com \\ Parisa Hajizadeh \\ English Department, Isfahan (Khorasgan) Branch, Islamic Azad University Isfahan (Khorasgan), Iran \\ E-mail: prs_hjzdh@yahoo.com
}

\section{Doi:10.5901/mjss.2015.v6n1s1p465}

\begin{abstract}
Learning the meaning and application of idiomatic expressions in English have always been challenging to the foreign language learners. This is mainly because such expressions display non-conventional and figurative senses. The present study aimed to investigate authentic, systematic and influential ways of exposing EFL learners to idiomatic expressions. To this end, short stories, as an important component of literature, and etymological elaboration, as a crucial aspect of language, were used to present the meaning of such expressions to L2 learners. Using Oxford Placement Test (OPT), 60 intermediate EFL learners studying at a private language institute were selected to participate in this study. They were assigned to three groups: control group (taught through conventional method), experimental group 1 (taught expressions through short stories), and experimental group 2 (taught through the application of etymological elaboration). Pre and posttests were administered at the beginning and at the end of the study, and the required data were analyzed by the use of SPSS. The findings revealed the considerable effect of short stories in raising L2 learners' awareness of the concepts underlying idiomatic expressions in comparison with the use of etymological elaboration. Moreover, it disclosed the positive effect of using etymological elaboration in a higher level of idiomatic development in contrast to mere teacher descriptive definition used in the control group.
\end{abstract}

Keywords: conceptual system, etymology, idiom, idiomatic competence

\section{Introduction}

Zarei and Rahimi (2012) believed that recently based on pedagogical point of view, figurative idioms have received a great deal of attention. This may be due to the fact that researchers are more aware of development of different facets of human language which were considered as being indispensable and highly frequent in everyday language use. Cooper (1999) proposes that idioms in foreign language learning have a vital role, and mentions that most English speakers say approximately 20 million idioms in their life. As a result, the application of appropriate figurative language would represent a native-like speech in every language. Simply put, all languages include many prescribed phrases and expressions which every speaker must learn.

Since language production concentrates on the ability to sequence multiword expressions, people are not accepted as proficient speakers of the foreign language until they master a range of idioms used in everyday communication. For the reason that being proficient in a foreign language mostly depends on using the idiomatic expressions in the everyday language of native speakers, many scholars (Danesy, 1992; Littlewood, 2000; Lakoff \& Johnson, 1980) have focused on the idiom studies in recent years.

Many researchers (Howarth 1998; Lattey 1986; Littlemore \& Low 2006; Nattinger \& DeCarrico 1992) proposed that many are aware of the impact of phraseological language to achieve a high level of communicative competence. Due to this, skilled non-native speakers of any language may be admired because of their control and proficiency of proper idiomatic language. Charteris (2002) believes figurative idioms are considered as a challenging task for L2 teachers and learners to the extent that the meanings of many idioms may not be derived from the sum of their grammatical and lexical parts. According to Zarei and Rahimi (2012), they are not thoroughly arbitrary so that one could merely learn them through blind memorization and this causes predicaments in the systematic instruction of idioms in L2 classrooms. Idioms spread through English with specific features and grant it with an astonishing variety so that "avoiding the use of idioms 
gives language a bookish, stilted, and unimaginative tone" (Cooper, 1999, p.86). They help language learners comprehend English culture, which has its roots in the customs and lifestyle of the English people, and provides an insight into English history (Crystal, 1997). Moreover, to enhance the learners' receptive skills along with their productive ones, educators have the obligation to teach the most frequent idioms to the learners. Regardless the real problems and complications linked with learning idioms, it is compulsory for the foreign language learners to learn idiomatic expressions. As a result, applying a proper approach to teaching idioms has always been of a great interest among language teachers. Therefore, linguists have inspired new insights into the field of applied linguistics suggesting more insightful and systematic approaches to L2 idioms acquisition (Boers, Demecheleer, \& Eyckmans, 2004).

\subsection{Objectives of the study}

Having idiomatic competence as one of the most problematic part of learning a second language, we, teachers, have to equip learners' minds for receiving and producing idiomatic expressions. This study intends to evaluate the effect of two different techniques of exposure to idioms on learners' conceptual and idiomatic comprehension. For this purpose, the researcher applied etymological explanation and literature in the form of short story as two techniques to teach the EFL (English as a foreign language) learners. Therefore, this study aims to first, investigate the probable effect of these two kinds of idiom presentation, and then to compare their effect on EFL learners' idiomatic competence.

Based on the prime objectives of the study, the following questions were going to be answered in this study:

1. Does using short stories in teaching idiomatic expressions improve intermediate EFL learners' comprehension of such expressions?

2. Does using etymological elaboration of idiomatic expressions improve intermediate EFL learners' comprehension of such expressions?

3. Is using short stories more effective than etymological elaboration in teaching idiomatic expressions to intermediate EFL learners?

\subsection{Significance of the study}

Idioms form an important part of any language and are essential to successful communication in every language. Therefore, they should be learnt and taught appropriately, as they are part of what is broadly considered as general English (Moreno, 2011).

With literature, in this study short stories, as a representation of a culture, and as a motivator in language learning and one of the most significant aspect of this study presents data in order to observe whether the incorporation of literature in foreign language classroom enhances the development of conceptual fluency and idiomatic competence. Major premises of this study are that literature provides a situation similar to authentic language, and that literature can be implemented as a rich source of meaningful language input, expressly when it comes to concepts and conceptual idioms which are the finest representatives of the concepts of each language. Besides, etymological elaboration can be attested in a model of story. Therefore, literature manifests itself as an ideal teaching medium very much demanded eminently in countries where opportunities for authentic language learning are limited. Moreover, literature and literary texts as well as conceptual fluency and idiomatic competence need to be given higher ranking in language planning for second language learning programs.

Additionally, studies from cognitive linguistics have focused on using etymological elaboration as a mnemonic approach to facilitate learners' L2 idiom retention to help L2 learners acquire idioms effectively and retain them for a longer time. It is a method that helps L2 learners to comprehend and remember figurative idioms by raising their awareness of the literal origins or source domains of those idioms. Such an approach has been proved effective in various paper-and pencil experiments (Boers, Demecheleer, Eyckmans, 2004).

The present study was an endeavor to scrutinize the role of two presentation techniques, idiomatic conceptualization through short stories and etymological elaboration. This study seems to have pedagogical value in the realm of idiom teaching and learning in that the findings may reveal which of these techniques is the most effective one in the comprehension of second language idioms. As a result, teachers of English can extend the operational procedure to improve idiom learning. In addition, EFL learners can partially overcome the problems they encounter in understanding and acquiring English idioms as well as their use in daily life. 


\section{Literature Review}

Based on the research done by Guduru in 2012, the disadvantaged learners' comprehension of idioms has a root in the exertion and the lack of context for using those expressions. Besides, Kiziltan (2012) believes in the absence of grammatical competence (words and rules), sociolinguistic competence (appropriateness) and strategic competence (appropriate use of communication strategies) as the chief consequence of comprehension troubles, learners endure for learning idioms.

According to the study of Zarei and Rahimi (2011), it can be mentioned that different techniques of presentation, such as etymology explanation, contextualization, and explicit instruction of vocabulary, have no distinctive impacts on the comprehension of L2 idioms. Moreover, etymological data is more helpful and advantageous to Iranian intermediate learners' idiom production compared with two other techniques. As result, as Zhang (2009) proposed, etymological data affects positively the productive information of target idioms.

Tabatabaei and Mirzaei (2014) proposed that the use of computers and multimedia glosses can be generally effective in language teaching and specifically in online L2 text comprehension and also idiom learning. In addition, in contrast with traditional idiom teaching in which learners are provided with limited authentic learning material and also monotonous idiom learning method, the incorporation of CALL to idiom learning and reading comprehension can develop into a dynamic learning process. In this way abundant learning materials from multiple sources, e.g. textual and pictorial, and various learning approaches which integrates classroom learning with online learning are adopted.

Rohani, ketabi, and Tavakoli (2012) studied about two similar groups of intermediate EFL learners were provided with unfamiliar idioms by the means of a story in written and video-graphic contexts. The participants were also given the definitions on a separate sheet to check. The participants' long-term and short-term comprehension and retention were then experimented and compared. The findings of the study indicated no significant difference between the performances of the two groups considering their short term retention, while considering long-term retention; the animation group i.e. the one exposed to the video-graphic context significantly outperformed the text group. The findings of the study also support the dual coding theory which emphasizes the role of mental imagery in retention.

Sadeghi, Vahid Dastjerdi and Ketabi (2010) also proposed that context is considered as an important role in the creation of idiomatic meaning. They also explained that language learners utilize different strategies; while absence of implicit knowledge of idioms is regarded as the main reason of their failure in comprehension and retention of the idiomatic meanings. Simultaneously, the degree of opacity between target and domain idioms affects the speed and ease of idiom understanding. Thus, dealing with idiomatic expressions just as collections of distinct disorganized lexical items, free from human conceptual and cultural system would result in negative transfer.

\section{Methodology}

\subsection{Participants}

The participants initially selected to take part in this study were 60 (20 in each group) adult EFL learners placed at intermediate level of English proficiency. The population from which the participants were selected included $100 \mathrm{EFL}$ learners studying at a private language school. OPT was conducted to have a homogenized sample. All the students in the study shared Persian as their mother tongue. The participants in both experimental and control groups belonged to the same cultural and socioeconomic background. They were all female, range of 18 to 28 years old.

\subsection{Materials}

Different materials were used for instruction in experimental groups. In order to instruct learners in experimental group 1 , about 36 short stories containing nearly 145 idioms, as a kind of literary piece, including the idiomatic expressions were used. It has been suggested, theoretically and practically, that literature can help students promote language learning in all its aspects in EFL classrooms (Beck \& McKeown, 2001; Oh, 2004; Perez \& Torres-Guzman, 2001). In this study, the book "Can You Believe It?, Book 3" written by Huizenga (2000), containing idioms embedded in different short stories was chosen to expose the learners to idiomatic expressions. The idioms were written in bold, and their definitions were presented at the end of the story. The author claimed that the book is compatible with comprehension approaches such as The Natural Approach, and the stories presented in the book provide the basis for great comprehensible input, he also stated that the book has been founded on two basic premises: 1) that everyone loves a good story, and 2) that vocabulary and idiom acquisition occurs more readily when new items are embedded in contexts and used in tasks that 
have meaning and purpose.

To expose learners in Experimental group 2 to the same idiomatic expressions, etymological elaborations were used. Idioms contain rich unique features of the language and culture, in other words many are culture or languagespecific. Learning idioms with this technique provides L2 learners with good opportunities to understand and acquire information about L2 cultural beliefs and customs as well as the linguistic features of the language (Liu, 2008). In line with this feature of idiomatic expressions, the researcher believed that through etymological elaboration the above features can be expressed. Having the origins of the idioms, "American Heritage Dictionary of Idioms" and "A Dictionary of the Origins and Stories of English Idioms" (Goshen, 2009) were used.

After OPT, the participants took part in a pretest, specifically designed to tap the participants' metaphorical competence in terms of idiomatic expression comprehension. The test was designed by the researcher, and it was piloted to assure whether the test's wording and clarity cause any problem for the respondents. 25 minutes was estimated as the appropriate time for the main steps of the research to administer pretest and posttest. This test required the participants to select the meaning of idiomatic statements from the given options. The calculated reliability of the test through Cronbach's Alpha was 0.899 , which shows the high reliability of the test. The third test, posttest, used in this study was the same as the pretest, administered to measure the participants' improvement in comprehension of idiomatic expressions. It should be pointed out that the order of the questions and choices was changed in the posttest to remove test practice effect.

\section{Procedure}

As mentioned before, the main participants who took part in this study were 60 Iranian students with the same level of language proficiency, intermediate level, studying English at a private language institute. Prior to the launching of the study, the participants were tested for their linguistic homogeneity, through the administration of OPT. English was taught to three groups: one control and two experimental groups, 3 times a week, 90 minutes each session. As the first main step of the study, the pretest was administered at the beginning of the study to measure the EFL learners' knowledge of idiomatic expressions. After administering the pretest each group was exposed to the idiomatic expressions separately. The instruction of idiomatic expressions for control group was done through the short conventional description done in normal classes of the institute based on their conventional curriculum by the teacher. The idioms were given to the EFL learners, and the teacher explained and defined them briefly. The description was followed by a simple example. The examples were mostly extracted directly from the dictionaries in order to be completely sure about the appropriateness of their use. The experimental group 1 and the experimental group 2, who were at the same pre -determined intermediate English proficiency level as the control group, were taught the same idiomatic expressions by presenting the short story and etymological elaboration, respectively .

The Posttest was administered at the end of the study to all the three groups, and the required data were then collected.

The whole study lasted for the period of about 3 months.

\section{Data Analysis}

Table 5.1 reports comparative descriptive statistics for the experimental and control groups.

Table 5.1: Descriptive Analysis of Variables

\begin{tabular}{llccccc}
\hline & & $\mathrm{N}$ & Minimum & Maximum & Mean & SD \\
\hline Control & Pretest & 20 & 0.00 & 4.00 & 2.0000 & 1.45095 \\
& Posttest & 20 & 4.00 & 9.00 & 6.7000 & 1.34164 \\
Short stories & Pretest & 20 & 0.00 & 5.00 & 2.4500 & 1.66938 \\
& Posttest & 20 & 10.00 & 19.00 & 14.5000 & 2.32832 \\
Etymological elaboration & Pretest & 20 & 0.00 & 4.00 & 1.9000 & 1.37267 \\
& Posttest & 20 & 9.00 & 15.00 & 11.7500 & 1.61815 \\
\hline
\end{tabular}

The mean in pretest of the control group was increased from 2.00 to 6.70 in posttest, in the experimental group 1 (short story) from 2.45 to 14.50, and in the experimental group 2 (etymological elaboration) from 1.90 to 11.75. 


\subsection{Inferential Statistics}

Kolmogorov- Smirnov test was performed to investigate the normality of distribution of scores. Based on the calculated significant level related to all tests, the normality of distribution confirmed. The results are shown in Table 5.2

Table 5.2: Kolmogorov-Smirnov Test for the Distribution of Scores

\begin{tabular}{lcccccc}
\hline & \multicolumn{2}{c}{ Control } & \multicolumn{2}{c}{ Short Story } & \multicolumn{2}{c}{ Etymological elaboration } \\
& Pretest & Posttest & Pretest & Posttest & Pretest & Posttest \\
\hline $\begin{array}{l}\text { Kolmogrov } \\
\text { Smirnov Z }\end{array}$ & 0.155 & 0.188 & 0.179 & 0.165 & 0.144 & 0.139 \\
Sig. (2- tailed) & 0.200 & 0.061 & 0.092 & 0.157 & 0.200 & 0.200 \\
\hline
\end{tabular}

Since the $p$-values calculated for all groups were more than $a(a=0.05)$, the normality of scores to be analyzed was confirmed. The normal distribution of scores paved the way for performing parametric test to compare the means.

\subsubsection{Comparison of the Means in the Pretest:}

A one way ANOVA was used to examine the equality of the three groups in the pretest.

Table 5.3: ANOVA for the Means in the Pretest

\begin{tabular}{lccccc}
\hline Pretest & Sum of squares & Df & Mean square & F & Sig \\
\hline Between groups & 3.433 & 2 & 1.717 & 0.760 & 0.472 \\
Within groups & 128.750 & 57 & 2.259 & & \\
Total & 132.183 & 59 & & & \\
\hline
\end{tabular}

As displayed in Table 5.3, the ANOVA calculation indicated that there was no significant difference between the means of the three pretests of control, experimental 1 (short story), and experimental 2 (etymological elaboration) groups ( $\rho=.472$ ). In other words, since $\rho$ - value is more than .05 , there is no significant difference between the group means.

\subsubsection{Comparison of the Means in the Posttest}

As shown in table 5.3, ANOVA calculations indicated that there was a significant difference between the means of the pretest in the mentioned three groups $(\rho=0.00)$. That is, since $\rho$-value is less than alpha $(0.05)$, there is a significant difference between the means of the pretest scores in the entire control group, experimental group one (short stories), and experimental group 2 (etymological elaboration).

Table 5.4: ANOVA for the Means in the Posttest

\begin{tabular}{lccccc}
\hline Posttest & Sum of squares & Df & Mean square & $F$ & Sig. \\
\hline Between groups & 626.033 & 2 & 313.017 & 95.437 & 0.000 \\
Within groups & 186.950 & 57 & 3.280 & & \\
Total & 812.983 & 59 & & & \\
\hline
\end{tabular}

\subsubsection{Comparison of the pretest and posttest in the Control Group}

As shown in table 5.4 the results from the pretest and pretest scores show that there was a significant difference between the means of the two performances of the control group. $(t=28.687, D F=19, \alpha=0.05, \rho=0.00)$. Since $\rho$-value is less than alpha, there is a significant difference between the means of pretest and pretest scores, which reveals the effectiveness of the instruction used for this group. 
Table 5.5: Paired-Samples test for the Control Group

\begin{tabular}{cccccc}
\hline & Mean & Std.deviation & T & Df & Sig.(2tailed) \\
\hline Posttest- pretest & 4.70 & 0.73 & 28.68 & 19 & 0.00 \\
\hline
\end{tabular}

The means are shown in Figure 5.1, and two different letters are the index of inequality between pre and posttest.

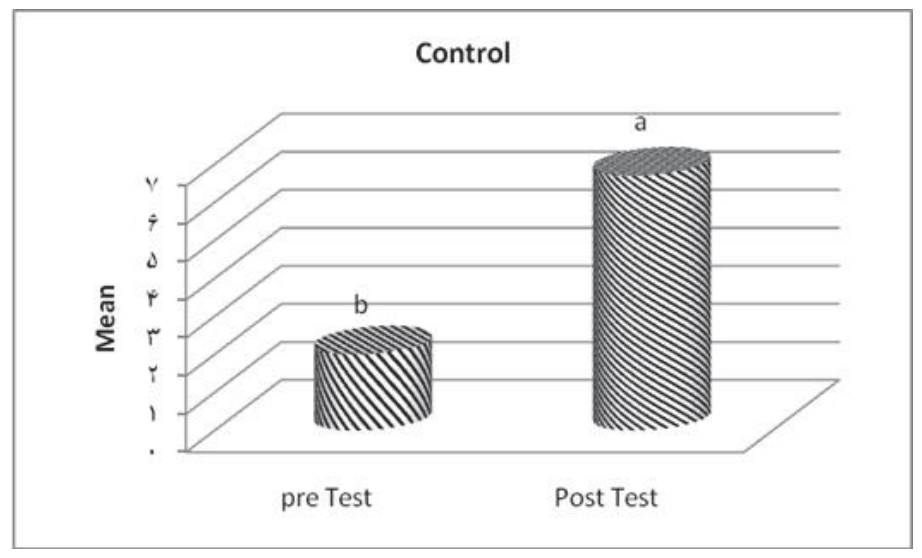

Figure 5.1 Comparisons of Means in the Control Group

\subsubsection{Comparison of the pretest and posttest in the Experimental Group 1}

Having the special material, short stories, as the main focus of this group, the effectiveness of it on improving conceptual fluency and comprehension of the idiomatic expressions had to be revealed. The results from the paired-samples test comparing pretest with posttest of experimental group 1, shows a significant difference between the means of the two performances, $(t=40.921, D f=19, \alpha=0.05, \rho=0.00)$. Since $\rho$-value was less than alpha, there was a significant difference between the means of the pretest and posttest scores, which reveals the effectiveness of the treatment used for the experimental group 1. The results are presented in table 5.6.

Table 5.6: Paired-Samples test for the Experimental Group 1

\begin{tabular}{cccccc}
\hline & Mean & Std.deviation & T & Df & Sig.(2tailed) \\
\hline Posttest-pretest & 12.05 & 1.31 & 40.92 & 19 & 0.00 \\
\hline
\end{tabular}

In Figure 5.2, the means are shown, and the letter $a$ and $b$ indicate the inequality of means in pre and posttest

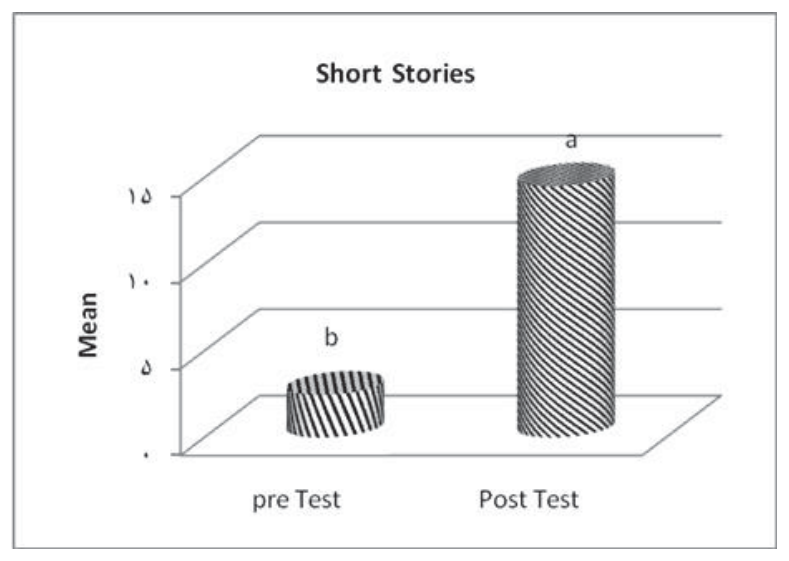

Figure 5.2: Comparisons of Means in the Experimental Group 1 


\subsubsection{Comparison of pretest with posttest in the Experimental Group 2}

To get the answer to the second research question about the usefulness of using etymological elaboration as the major material of teaching idiomatic expressions in experimental group 2 a paired- samples test was used. The results indicated a significant difference between the means of the pre and posttest's scores ( $t=32.667, D f=19, \alpha=0.05, \rho=0.00)$. Since $\rho$ value was less than alpha, there was a significant difference between the means of the pre and posttest's scores, which showed the effectiveness of the treatment in the experimental group 2. The results are presented in table 5.7.

Table 5.7: Paired- Sample Test for the Experimental Group 2

\begin{tabular}{cccccc}
\hline & Mean & Std.deviation & T & Df & Sig.(2tailed) \\
\hline Posttest-pretest & 9.85000 & 1.34849 & 32.667 & 19 & 0.000 \\
\hline
\end{tabular}

The means and the inequality between pre and posttests are shown in Figure 5.3

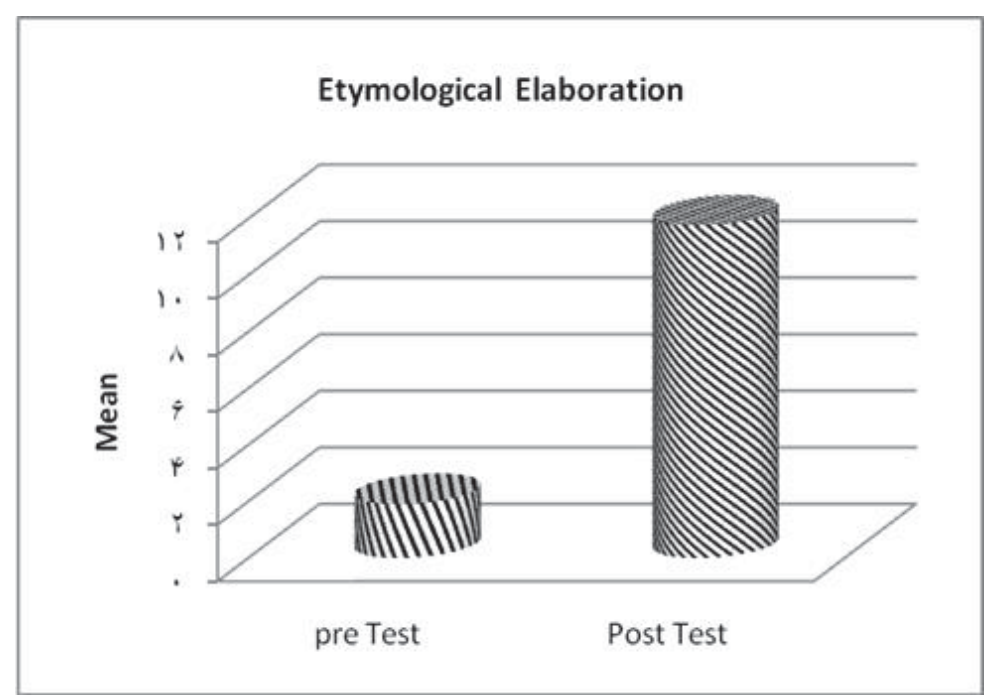

Figure 5.3: Comparison of Means in the Experimental Group2

\subsubsection{Comparison of All Three Groups}

To get the answer of the third question, it was needed to determine which group was better improved. Following Levene's test to find out the homogeneity of variances (table 5.8), Duncan's test was chosen as a type of post HOC test.

Table 5.8: Test of Homogeneity of Variances

\begin{tabular}{cccc}
\hline Levene Statistic & Df1 & Df2 & Sig. \\
\hline 2.994 & 2 & 57 & 0.058 \\
\hline
\end{tabular}

As shown in table 5.8 Duncan's test calculations revealed that none of these groups acted the same and there is a significant difference between them. The results indicated that the methods used in control group, experimental group 2 (etymological elaboration), and experimental group 1 (short stories), with the means of 6.70, 11.75, and 14.50 , have the least to the most impact on improving the learners' metaphorical competence. 


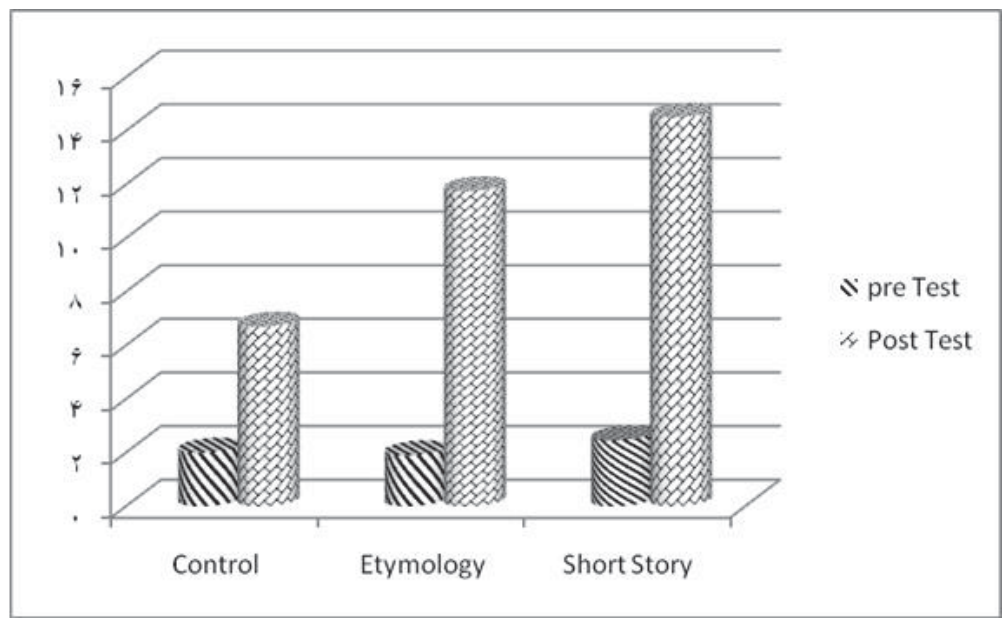

Figure 5.4: Comparison of all Groups

\subsection{Summary}

Based on all the analysis done above, it could be concluded that there was a significant difference between the mean scores of the three sets of scores on pre and posttest. The participants on the posttest showed more idiomatic knowledge than they did on the pretest, i.e., participants' metaphoric competence and comprehension of idiomatic expressions, in all three groups improved during the course, with all the conventional curriculum and special treatments in the experimental groups.

According to the analysis, the comparison of means in Experimental group 1 showed the development of students in idiomatic expressions' comprehension; so, this result rejected the first null hypothesis, which was "Using short stories in teaching idiomatic expressions does not improve intermediate EFL learners' comprehension of such expressions." Besides, the comparison of means in Experimental group 2, presented the development of learners' metaphoric competence, and the second null hypothesis of this research, "Using etymological elaboration of idiom expressions in teaching them does not improve intermediate EFL learners' comprehension of such expressions", was rejected

In conclusion and with the comparison of all the results extracted from the students' performance in all these three groups, learners did the best in Experimental group 1. Thus, it could be concluded that the third null-hypothesis, "There is no difference between using short stories and etymological elaboration of idiomatic expressions in teaching them to intermediate EFL learners", was rejected.

The following figure reveals the answer to the research questions briefly.

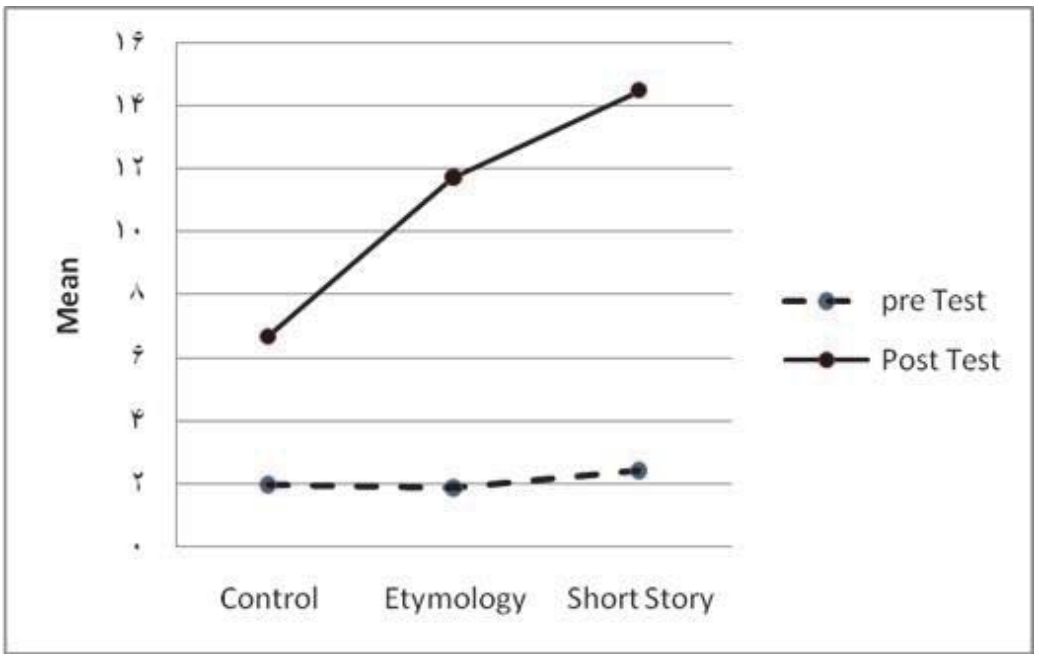

Figure 5.5: The Means in all Groups 


\section{Conclusion and Discussion}

Figurative language goes beyond the literal sense of words in order to establish images to furnish and present things transparently. In order to enter such a crucial stage of broad comprehension, L2 learners need to develop metaphoric competence and conceptual fluency. To recap, developing the skills to produce or comprehend idioms is a sign of the emergence of metaphoric competence. Some abilities such as deferring the use of literal-referential strategies and producing novel figurative expressions and providing the context to use the appropriate idiomatic expression can be held as the representatives of metaphoric competence (Levorato, 1993; Levorato \& Cacciari, 1992).

In this study, the first research question was to evaluate if this approach would be better for the progress and improvement of L2 learners' idiomatic competence compared with the traditional way of teaching idiomatic expressions. Considering the first research question, the related data were elicited for the subsequent analysis. After having analyzed the descriptive and inferential statistics for both control and experimental group 1 on the pre and posttest, the results indicated that the null hypothesis can be safely rejected. The same as pretests, the computed p-value exceeded the prespecified alpha level $(\alpha=0.05)$ which indicates that there is no significant difference between the means of the pretest scores for both the control and experimental group 1. After pretest was executed, the guidelines and instructions were provided. Because of its rich conceptual texts, short story was used in this study. It helped students how some of these idioms are used in real-life like concepts.

Considering the posttests' results, the calculated p-value $(0.000)$ was less than the pre-specified alpha level $(a=0.05)$, which evidently denotes that there was a significant difference between the performance of the participants on the posttest in the control and experimental group 1, regarding idiomatic expressions' understanding and idiomatic competence.

The result driven from the analysis of data for the first question of this study is in line with that of Littlewood (2000), who emphasizes the importance of using literature in EFL classes through explaining the lack of authentic situation for language in the classroom. He states that it is so difficult to provide such contexts in the community of non-native speakers. To fill this gap, he suggests the events created by language. Story books are filled with context of situations and they are able to surpass the artificial classroom situation.

Hashemian and Talebinezhad (2007) believed that one of the principle explanations why L2 learners are not practically fluent and figuratively competent in English could be due to this point that they have never been properly and correctly exposed to the English conceptual concepts and idiomatic expressions even up to the highest levels of language learning. Because Iranian students in Iran are not exposed to native like English in the social context, not sufficient chances are provided for them to perceive different usages of English and thereby to involve in and experience authentic material in context. As a result, Iranian students the same as other EFL learners require a meaningful context to work from and to which they can relate what they learn.

The starting point of this study was the problem of how well non-native learners of English cope with the meanings behind idiomatic expressions so that they could make out for themselves the concrete and abstract senses embodied in such a construction. Therefore, the question here was whether teaching could provide learners in a foreign language setting with this rich experience so that learners would also be able to work out the meanings behind such constructions for themselves. The novel approach the researcher thought to put into experiment was to expose the EFL learners to the real story behind the idiomatic expressions.

After having analyzed the descriptive and inferential statistics for the control and experimental group 2 on the pre and posttests, the results revealed that the null hypothesis should be rejected. As for the pretests, the computed p-value exceeded the pre-specified alpha level $(\alpha=0.05)$, which indicates that there was no significant difference between the means of the pretest scores for both the control and experimental group 2. After having the pretest, the instructions were provided. As it was described before, etymological elaboration was used for this group.

Considering the posttests, the calculated $p$-value ( 0.000$)$ was less than the pre-specified alpha level $(\alpha=.05)$, which vividly points to the fact that there was a significant difference between the performance of the participants on the posttest in the control and experimental group 2 in terms of idiomatic expressions' comprehension and metaphoric competence.

The results of the posttests revealed the experimental group who received etymological elaborations performed better in learning idioms than the other group. The results of this study indicate that etymological information improves idiom learning of the students and this finding is in line with Boers (2004), who stated that the mnemonic effects of etymology to idioms are more than the other techniques. Boers (2001) also said that if idioms which derived from specific source are associated with the original usage they will be kept more in the memory of students.

On the other hand, the finding of this part of the study is not consistent with the one done by Zhang (2009), who found that etymology had no significant influence on L2 idiom comprehension while it was effective in the production of 
target idioms. It should be noted that there is a difference between this study and Zhang (2009) in that he examined the effect of etymological elaboration on the learning of idioms in web-based and on-line learning environments.

A quick look at the test results gained by both the experimental groups' participants reveals that work on short stories greatly improved their comprehension of idiomatic expressions. It seems that the enhanced recognition of concrete/abstract meanings in idiomatic expressions has been the result of participants' establishment of meaningful connections between concrete/abstract conceptual stimuli presented to them.

Perhaps, the most important objective of the present study was to observe whether a conceptual representation of concrete meaning could guide learners' inferences of related abstract significance, compared with the effect of etymological elaboration on improving learners' idiomatic expressions' comprehension. The results clearly demonstrate that short stories with the special feature of conceptualization can enhance their idiomatic competence. This is evident in the highly significant results achieved by the participants in experimental group (1) in posttest compared to the lower gain by experimental group (2). Since no relevant literature, regarding the third question of this study was found the following claim is inferred by the researcher based on the result extracted from this study.

The researcher put the reason of the higher achievement of participants in the experimental group 1, compared with the experimental group 2, on account of an essential feature of literature, as it is stated by Heath (1996), that "literature has no rival in its power to create natural repetition, reflection on language and how it works, and attention to audience response on the part of learners" (p. 776). So, it works better for teaching idiomatic expressions and metaphoric concepts as the difficult-but important- aspect of language, being measured against the use of etymological elaboration to teach those concepts.

From what was observed, and the results of inferential statistics analysis, the performance in experimental group (1) with the mean of 14.50, is higher than the performance in experimental group (2) with the mean of 11.75 . Hence, the third null hypothesis was also rejected, and the following directional hypothesis comes forward:

There is a difference between using short stories and etymological elaboration in teaching idiomatic expressions to intermediate EFL learners.

Since the area of idiom research provides a very interesting aspect of $L 2$ acquisition, they have been the subject of much research. According to Boers (2000), the results of several studies have demonstrated that learners' familiarity with idioms can have a significant effect on their communication. Idioms a class of multi-word units "which pose a challenge to our understanding of grammar and lexis that has not yet been fully met" (Fellbaum, 2006, p. 349). On the other hand, when an idiom is encountered for the very first time, language users have no choice but to decipher its meaning from the meaning of the constituents, usually doing so by taking into account the most salient, or prominent, meanings first ( Peleg \& Giora 2000). It is worth mentioning that, if EFL learners lack the necessary linguistic and cultural knowledge, although they may be able to interpret the idioms literally, learning all figurative language, even transparent idioms will be one of the most problematic aspects of language for them. As Fernando and Flavell, (1981) believed, one of the most important principles for categorizing idioms has been its non-compositional nature. It is believed that its meaning cannot be inferred from adding up the individual elements. As a result, the meaning of idioms seems to be completely arbitrary (Cooper, 1999).

Summing up, three main aspects could be highlighted. Firstly, teaching figurative language in general and idioms in particular is very complex and therefore, poses many problems not only from a pedagogical point of view, but from a cultural one. It is clear, however, that these fixed expressions, due to their high frequency in discourse should be included in the curriculum and not be relegated to a secondary position. Secondly, it is crucial to teach these idioms as part of a culture, reflection of beliefs of a community. This study shows that studying the etymology is essential for that purpose, since these expressions were coined in a specific moment and because of cultural reasons that cannot be found out by merely analyzing the constituent parts of the expression itself. Also, the contextualization of the idioms can be much effective in the comprehension of such expressions.

\section{References}

Alexander, R.J. (1987). Problems in understanding and teaching idiomaticity in English. Anglistik und Englischunterricht, 32, 105-122.

Beréndi, M., Csábi, S. \& Kövecses, Z. (2008). Using conceptual metaphors and metonymies in vocabulary teaching. In F. Boers \& S. Lindstromberg (Eds.), Cognitive Linguistic Approaches to Teaching Vocabulary and Phraseology (pp. 65-99). Berlin: Mouton de Gruyter.

Boers, F. (1999). Learning vocabulary through metaphoric awareness. Études et Travaux, 3, 53-65.

Boers, F. (2000). Metaphor awareness and vocabulary retention. Applied Linguistics, 21, 553-571.

Boers, F., Demecheleer, M., \& Eyckmans, J. (2004). Cross-cultural variations as a variable in comprehending and remembering figurative idioms. European Journal of English Studies, 8(3), 375-388. 
Charteris-Black, J (2002). Second language proficiency: a comparative study of Malay and English. Applied Linguistics 23(1), $104-133$.

Cooper, T. c. (1999). Processing of idioms by L2 learners of English. TESOL Quarterly, 33(2), 233-262.

Cronk, B. C. \& Schweigert, W. A. (1992). The comprehension of idioms: The effects of familiarity, literalness, and usage. Applied Psycholinguistics, 13(2), 131-146.

Crystal, D. (1997). English as a global language. Cambridge: Cambridge University Press.

Danesi, M. (1992). Metaphorical competence in second language acquisition and second language teaching: The neglected dimension. In: J. E. Alatis (ed.) (1992). Georgetown university round table on languages and linguistics. Washington DC: Georgetown University Press.

Hashemian, M. \& Talebinezhad, M.R. (2007). The Development of Conceptual Fluency and Metaphorical Competence in L2 Learners. Linguistik Online, 30, 1-7.

Herrera, H., \& White, M. (2000). Cognitive linguistics and the language learning process: A case from economics. Estudios Ingleses de la Universidad Complutense, 8, 55-78.

Howarth, P. (1998). Phraseology and second language proficiency. Applied Linguistics, 19(1),24-44.

Huizenga, J. (2000). Can you believe it? Stories and idioms from real life: Book 1. New York, NY: Oxford University Press.

Lackoff, G. \& Johnson, M. (1980). Metaphors we live by. Chicago: University of Chicago Press.

Lattey, E. (1986). Pragmatic classification of idioms as an aid for the language learner. IRAL, 23(3), 217-233.

Littlemore, J \& Low, G. (2006). Metaphoric competence, second language learning, and communicative language ability, Journal of Applied Linguistics, 27(2), 268-294.

Littlewood, W. (2000). Literature in the school: Foreign-language course. (Eds.) Brumfit, C.J., \& Carter, R.A. Literature and language teaching. Oxford: OUP.

Nattinger, J. R., \& DeCarrico, J. S. (1992). Lexical phrases and language teaching. Oxford: Oxford University Press.

Nippold, M. A., \& Rudzinski, M. (1993). Familiarity and transparency in idiom explanation: A developmental study of children and adolescents. Journal of Speech and Hearing Research, 36(4), 728-737.

Rohani, Gh. , Ketabi, S. and Tavakoli M. (2012). The Effect of Context on the Iranian EFL Learners' Idiom Retention. English language teaching journal 5 (9), 53-66.

Sadeghi, B., Vahid Dastjerdi, H., \& Ketabi, S. (2010). Patterns of Persian EFL learners' Comprehension of Idiomatic expressions: Reading strategies and cross cultural mappings in focus. Asian Social Science, 6(8), 81-99.

Tabatabaei, O. and Mirzaei, M. (2014). Comprehension and Idiom Learning of Iranian EFL Learners. Journal of Educational and Social Research MCSER Publishing, Rome-Italy 4(1)

Velasco Sacristan, M. 2005. A critical cognitive-pragmatic approach to adverstising gender metaphors. Intercultural pragmatics 2(3), 219-252.

Zarei,A. and Rahimi N. (2012). Idioms Etymology, Contextual Pragmatic Clues, and Lexical Knowledge in Focus. Lambert Academic Publishing. 